\title{
Electromyography and recovery of the blink reflex in involuntary eyelid closure: a comparative study
}

\author{
M Aramideh, J L A Eekhof, L J Bour, J H T M Koelman, J D Speelman, \\ $B$ W Ongerboer de Visser
}

\begin{abstract}
Electromyographic (EMG) activity of orbicularis oculi and levator palpebrae muscles was recorded to study the origin of involuntary eyelid closure in 33 patients. The evoked blink reflex in all patients and in 23 controls was also studied. To examine the excitability of facial motoneurons and bulbar interneurons in individual patients and to compare the results with EMG findings, $R 1$ and $R 2$ recovery indices were calculated in all subjects, as the average of recovery values at $0 \cdot 5,0.3$, and 0.21 second interstimulus intervals. Based on EMG patterns, the patients were divided into three subclasses: EMG subclass 1, 10 patients with involuntary discharges solely in orbicularis oculi muscle; EMG subclass 2, 20 patients with involuntary discharges in orbicularis oculi and either involuntary levator palpebrae inhibition or a disturbed reciprocal innervation between orbicularis oculi and levator palpebrae; EMG subclass 3, three patients who did not have blepharospasm, but had involuntary levator palpebrae inhibition in association with a basal ganglia disease. The total patient group showed an enhanced recovery of both $R 1$ and $R 2$ components compared with controls. Although 30 out of 33 patients had blepharospasm (EMG subclasses 1 and 2), $\mathrm{R} 1$ recovery index was normal in $64 \%$ and $R 2$ recovery index was normal in $54 \%$. Patients with an abnormal $R 2$ recovery index had an abnormal $R 1$ recovery index significantly more often. All patients from EMG subclass 1 had an abnormal R2 recovery index, whereas all patients from EMG subclass 3 had normal recovery indices for both $R 1$ and $R 2$ responses. Seventy five per cent of the patients from EMG subclass 2 had normal recovery indices. The results provide further evidence that physiologically blepharospasm is not a homogeneous disease entity, and indicate that different pathophysiological mechanisms at the suprasegmental, or segmental level, or both are involved.
\end{abstract}

$(\Im$ Neurol Neurosurg Psychiatry 1995;58:692-698)

Keywords: dystonia; blepharospasm; blink reflex recovery
Blepharospasm is a form of focal dystonia, with an aetiology and underlying pathophysiological mechanisms that are still obscure. Blepharospasm may occur in diseases of the basal ganglia or in association with upper brain stem abnormalities. ${ }^{1-8}$ In most patients, however, it is idiopathic in origin.

One investigation technique that has contributed to our understanding of blepharospasm is the recorded blink reflex recovery, which indicates the state of excitability of the facial motoneurons and bulbar interneurons. Electrical stimulation of the supraorbital nerve elicits a blink reflex that consists of two components; an early ipsilateral response, $\mathrm{R} 1$, mediated through the pons by an oligosynaptic pathway and a late bilateral response, R2, relayed through a polysynaptic medullary pathway..$^{9-13}$ Motoneurons of the facial nerve constitute the final common path for both responses. The recovery curve, also known as excitability cycle, of $R 1$ and $R 2$ responses can be obtained by applying two stimuli, conditioning and test, to the supraorbital nerve at different interstimulus intervals. ${ }^{14}$ The excitability of the blink reflex circuit may then be assessed by comparing the size of the test response with that of the conditioning response, which is partly dependent on the functional integrity of the suprasegmental structures. In healthy subjects, the R2 test response shows pronounced suppression at shorter interstimulus intervals, ${ }^{10}$ whereas patients with cortical lesions may exhibit an enhanced habituation and patients with basal ganglia disorders a diminished habituation (enhanced recovery) of the response..$^{11}$ Previous work has shown an enhanced recovery of the $R 2$ response in patients with blepharospasm, which suggests hyperexcitability of the bulbar interneurons. ${ }^{15-18}$

By simultaneous recording of the electromyographic (EMG) activities from the orbicularis oculi and levator palpebrae muscles, we have shown that patients with blepharospasm are not a homogeneous group, because differing abnormalities of EMG patterns are found among these patients. ${ }^{19} 20$

In the present study, we examined the recovery of $R 1$ and $R 2$ responses and EMG activity of orbicularis oculi and levator palpebrae muscles in patients with involuntary eyelid closure. The aim of the study was: (1) to evaluate the state of excitability of facial motoneurons and bulbar interneurons in individual patients with a certain EMG abnormality; (2) to see whether there is a correlation 
Table 1 General characteristics of the patients examined

\begin{tabular}{lc}
\hline Number of patients (n) & 33 \\
Women/men & $22 / 11$ \\
Mean age (y) (range) & $67(37-88)$ \\
Mean age at onset (y) (range) & $57(25-77)$ \\
Mean duration of illness (y) (range) & $9(1-20)$ \\
Type of dystonia: & 17 \\
focal (n) & 13 \\
segmental (n) & 7 \\
Treatment at time of study: & 3 \\
$\quad$ Botulinum toxin type A (n) & \\
Medication (n) & \\
\hline
\end{tabular}

between clinical data, EMG subclass, and recovery values, and (3) to provide additional information on possible underlying pathophysiological mechanisms of blepharospasm.

\section{Materials and methods}

Thirty three patients, 22 women and 11 men (mean age 67 (range 37-88) years) with involuntary eyelid closure were studied. Table 1 summarises the clinical data of the patients. At the time of the study, seven patients were already under treatment with botulinum $\mathrm{A}$ toxin (Dysport) but in all patients voluntary and reflex activity of the orbicularis oculi could easily be recorded. The control group consisted of 23 subjects (six women and 17 men) with a mean age of 49 (range 18-73) years.

The method of EMG recording from orbicularis oculi and levator palpebrae muscles has been reported previously. ${ }^{19} 20$ Blink reflex studies were performed with the subject lying supine. Electrical stimuli were applied to the supraorbital nerve at the supraorbital foramen. Surface recording electrodes were placed over the lower portion of orbicularis oculi ipsilateral to the stimulation site. A Grass stimulator was used to apply constant current pulses with a duration of $0.2 \mathrm{~ms}$. The early and late blink reflexes were evoked with stimulus intensity adjusted to three times the threshold of the R2 response. Subjects were requested to close their eyes gently during stimulation, and responses with artefacts due to involuntary movements were rejected. Paired stimuli (conditioning and test) were delivered at interstimulus intervals of $0.5,0.3$, and 0.21 seconds and six trials were performed at each interval. Between successive trials, a rest period of at least 30 seconds was maintained to avoid habituation of the response. The low pass filter was set at $3 \mathrm{kHz}$ and the high pass filter at $1 \mathrm{~Hz}(6 \mathrm{~dB} / \mathrm{oct})$. The sweep time was kept at $200 \mathrm{~ms}$. All responses were stored digitally on a PDP $11 / 73$ computer. In an off line analysis procedure, performed fully automatically, reflex responses were digitally band pass filtered within a range of more than $100 \mathrm{~Hz}$ to minimise DC offsets and slow eye drifts and below $900 \mathrm{~Hz}$ to reduce the high frequency noise. The responses were then full wave rectified and the average of six trials was computed for each interstimulus interval. Peak amplitude of R1 was calculated within a window from 10 to $25 \mathrm{~ms}$ to avoid stimulation artefact, and that of R2 within a window from 32 to $90 \mathrm{~ms}$. The average rest activity level was established within a window from 150 to 200 ms and subtracted from the average response. For each subject, $\mathrm{R} 1$ and $\mathrm{R} 2$ recovery values were obtained by calculating the size of the test response as a percentage of the conditioning response at each interstimulus interval.

R1 recovery index was calculated in each subject as the mean value of peak amplitude recovery, obtained at interstimulus intervals of $0.5,0 \cdot 3$, and 0.21 seconds. The $R 2$ recovery index was calculated in the same way. The upper limit of normal for R1 and R2 was defined as the mean $+2 \cdot 5 \mathrm{SD}$.

\section{STATISTICAL ANALYSIS}

A correlative study was performed between the clinical data, EMG subclasses, and blink reflex recovery indices by means of KruskallWallis and $\chi^{2}$ tests, with the SPSS statistical program. Differences and correlations were considered significant at $P$ values $<0.05$.

\section{Results}

Table 2 summarises the results of the recorded EMG and blink reflex recovery.

\section{EMG FINDINGS}

According to the EMG patterns, patients were divided into three subclasses. Ten patients belonged to EMG subclass 1, in whom EMG recording showed involuntary discharges in the orbicularis oculi alone, with normal tonic activity of levator palpebrae and normal reciprocal innervation of orbicularis oculi and levator palpebrae. EMG subclass 2 consisted of 20 patients. Besides involuntary

Table 2 Mean values of $R 1$ and $R 2$ recovery indices in patients and controls

\begin{tabular}{lllllll}
\hline Group & $\begin{array}{l}\text { No of } \\
\text { subjects }\end{array}$ & $\begin{array}{l}\text { Focal } \\
\text { segmental } \\
\text { dystonia }\end{array}$ & $\begin{array}{l}\text { Mean } R 1 \\
\text { index } \\
\text { (range) }\end{array}$ & $\begin{array}{l}\text { No of } \\
\text { abnormal } \\
\text { R1 indices }\end{array}$ & $\begin{array}{l}\text { Mean } R 2 \\
\text { index } \\
\text { (range) }\end{array}$ & $\begin{array}{l}\text { No of } \\
\text { abnormal } \\
R 2 \text { indices }\end{array}$ \\
\hline $\begin{array}{l}\text { Controls } \\
\text { Patients: }\end{array}$ & 23 & - & $78(36-120)$ & - & $22(11-42)$ & - \\
$\begin{array}{l}\text { Whole group } \\
\text { EMG subclass: }\end{array}$ & 33 & $17 / 13$ & $125(35-227)^{\star \star \star}$ & $10 \dagger$ & $42(6-108)^{\star \star \star}$ & 15 \\
$\quad 1$ & 10 & $3 / 7$ & $161(73-278)^{\star \star \star}$ & 5 & $60(45-79) \star \star \star$ & 10 \\
2 & 20 & $14 / 6$ & $118(35-215)^{\star}$ & 5 & $32(6-108)$ NS & 5 \\
3 & 3 & - & $96(74-107)$ NS & 0 & $60(28-37)$ NS & 0 \\
\hline
\end{tabular}

The recovery indices are given in percentages. ${ }^{\star} \mathrm{p}<0.05 ;{ }^{\star \star \star} \mathrm{p}<0.001 v$ controls.

†R1 could not be recorded in five patients, two from EMG subclass 1 and three from EMG subclass 2 . 
discharges in orbicularis oculi, EMG recording in these patients disclosed either episodes of involuntary inhibition of tonic activity of levator palpebrae or a disturbed reciprocal innervation of orbicularis oculi and levator palpebrae. EMG subclass 3 consisted of three patients. Abnormality in these patients was characterised by solely involuntary inhibition of levator palpebrae, with normal activity of orbicularis oculi and normal reciprocal innervation of orbicularis oculi and levator palpebrae muscles. These three patients had, therefore, no blepharospasm.

\section{BLINK REFLEX FINDINGS}

Controls

There was pronounced variability in $R 1$ recovery from one subject to another at different interstimulus intervals. The mean recovery of $\mathrm{R} 1$ at the 0.5 second interval was $69 \%$ and this increased to $78 \%$ at 0.21 seconds. Table 2 shows $\mathrm{R} 1$ and $\mathrm{R} 2$ recovery indices. The mean value of the $R 1$ recovery index was $78 \%$ (range, $36 \%-120 \%$ ), and the upper limit of normal was $135 \%$. The R2 recovery curve showed less variability. By contrast with $\mathrm{R} 1$, recovery of R2 gradually decreased from $29 \%$ at the 0.5 second interval to $15 \%$ at $0.21 \mathrm{sec}-$ onds. The R2 recovery index had a mean value of $22 \%$ (range $11 \%-42 \%$ ), and the upper limit of normal was $43 \%$.

\section{Patients}

In five patients, the $R \mathbf{l}$ recovery index could not be calculated because the amplitude of R1 was too low with respect to the noise. Recovery of R1 gradually increased from $117 \%$ at the 0.5 second interval to $137 \%$ at 0.21 seconds. Table 2 shows $\mathrm{R} 1$ and $\mathrm{R} 2$ recovery indices for the total patient group and for the three EMG subclasses. The R1 recovery index in the patient group differed significantly from that in the control group ( $P$ $<0.001)$. Recovery of R2 gradually decreased from $50 \%$ at the 0.5 second interval to $31 \%$ at 0.21 seconds. $\mathrm{R} 2$ recovery index in the patient group was significantly higher than that in the control group $(P<0.001)$.

Considering the individual data, 18 of 28 patients $(64 \%)$ had a normal R1 recovery index, and 18 of 33 patients (54\%) had a normal R2 recovery index (table 2). A significant number of patients with an abnormal R1 recovery index also had an abnormal $R 2$ recovery index $(P=0.01$, Yates corrected test).

Considering the data from different EMG subclasses, the $R 1$ recovery index differed statistically from control subjects in EMG subclass $1(P<0.001$, table 2$)$ and less so in EMG subclass $2(P<0.05)$. The $R 2$ recovery index differed statistically from control subjects only in EMG subclass $1(P<0.001)$. All the patients from EMG subclass 1 had an abnormal R2 recovery index, and $50 \%$ of them also had an abnormal R1 recovery index. Dystonia of other cranial or cervical muscles was found significantly more often in EMG subclass $1(P<0.01$, table 2$)$. Figure 1 shows an example of abnormal R1 and R2 recovery curves in one of the patients from this group. All three patients from EMG subclass 3 had normal $R 1$ and R2 recovery indices, whereas all had associated basal ganglia disease; one had progressive supranuclear palsy, and two had multiple system atrophy. Interestingly, 15 patients (75\%) from EMG subclass 2 had a normal R2 recovery index. Figure 2 shows normal R1 and R2 recovery curves in one of the patients from this group.

\section{Discussion}

We investigated the recovery of $R 1$ and $R 2$ components of the blink reflex in patients with involuntary eyelid closure, as one single group or divided into three subclasses according to the EMG patterns of orbicularis oculi and levator palpebrae muscles. Patients with EMG subclass 1 had involuntary discharges solely in orbicularis oculi muscle. ${ }^{20}$ EMG subclass 2 consisted of patients with involuntary discharges in orbicularis oculi, accompanied by either involuntary inhibition of levator palpebrae motor activity, or a disturbed reciprocal innervation of orbicularis oculi and levator palpebrae. In an earlier report, ${ }^{20}$ we proposed the term "blepharospasm-plus" to designate those patients with this type of EMG abnormality. The patients from EMG subclass 3 had solely involuntary inhibition of levator palpebrae, ${ }^{21} 22$ also known as apraxia of eyelid opening, ${ }^{23}$ with no clinical or EMG signs of blepharospasm. ${ }^{1920} \mathrm{We}$ included these patients in the present study because the differentiation between blepharospasm and involuntary levator palpebrae inhibition is not always easy to make clinically and synchronous EMG recording from orbicularis oculi and levator palpebrae is often required. ${ }^{20}$

In controls, $\mathrm{R} 1$ recovery showed some variability between subjects at all three interstimulus intervals. From 0.5 to 0.21 second intervals, R1 recovery showed a gradual enhancement, with relatively less suppression at 0.3 seconds. By contrast, $\mathrm{R} 2$ recovery showed almost no interindividual variability and from 0.5 to 0.21 second intervals there was a gradual increase in suppression. Also, in the total patient group the recovery of $\mathrm{R} 1$ differed from that of R2. There was often an absolute increase of $\mathrm{R} 1$ test response when the interval was shortened from 0.5 to 0.21 seconds, whereas the R2 test response diminished at shorter intervals. Such a difference in the properties of $\mathrm{R} 1$ and $\mathrm{R} 2$ responses has also been found in other studies. ${ }^{24-26}$ The same facial nerve motoneurons generate both responses and the final efferent pathway is common. Therefore, the difference in the recovery behaviours of $R 1$ and $R 2$ responses, in both the controls and patients, should be caused by the bulbar interneurons. Yet it cannot entirely be explained by the difference in the number of bulbar interneurons through which these responses are relayed, and is probably also dependent on the individual properties of the interneurons, their relation to one another, and the suprasegmental drives on them. A difference in presynaptic 
Figure 1 (A) Rectified and averaged $(6 \times)$

EMG responses at

intervals $0 \cdot 5,0 \cdot 3$, and

0.21 seconds between the conditioning and test stimuli in a patient from EMG subclass 1. Recovery curve for $R 1$ (B) and R2 (C) in the same patient. The recovery of $R 1$ and $R 2$ responses are enhanced at all three intervals. ISI = interstimulus interval; $t / c$ ratio $=$ test

response/conditioning response.
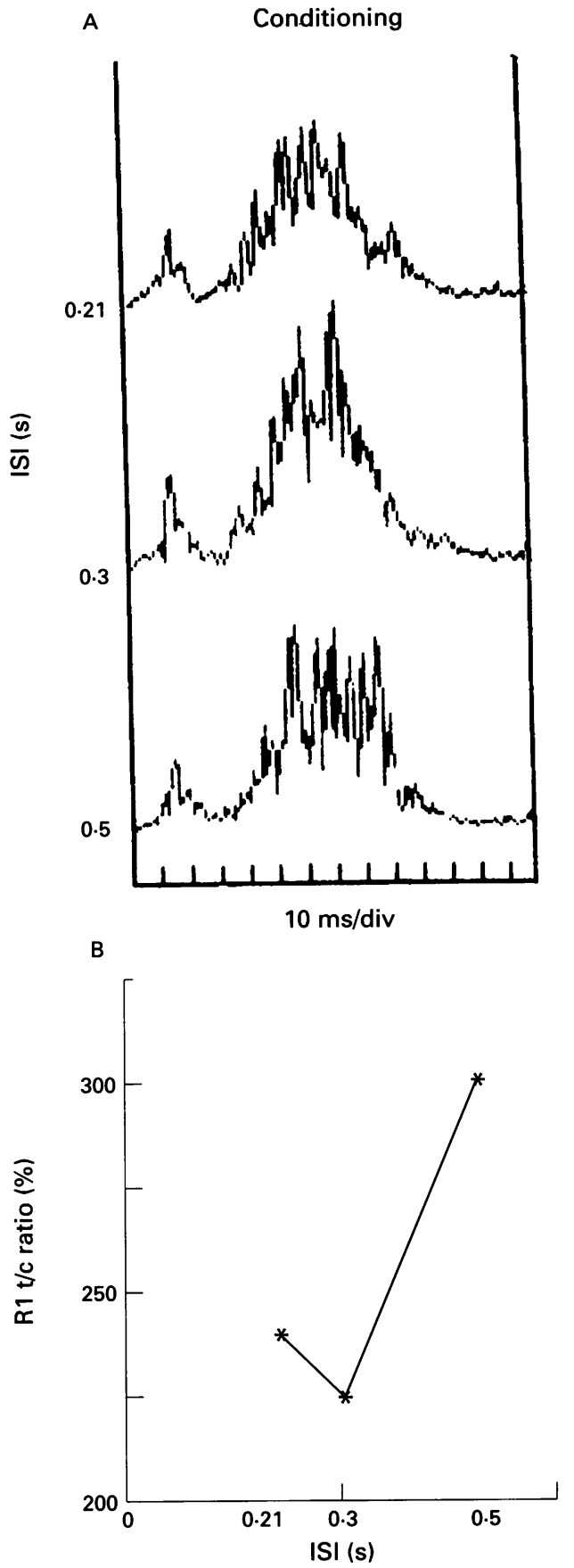

inhibition at the primary cutaneous afferent terminals ${ }^{27} 28$ also cannot be excluded.

The enhanced recovery of the $\mathrm{R} 2$ response found in the total patient group confirms the results of previous authors. ${ }^{15-18} \mathrm{We}$ also found an increased recovery of the $R 1$ response, whereas Tolosa et al ${ }^{15}$ noted a normal R1 recovery and the other authors did not report on the features of $R 1$ recovery in patients with blepharospasm. ${ }^{16-18}$ Although these conflicting results and the lack of information on this issue may require further investigation, some features of the recorded blink reflex are in favour of an enhanced excitability of the oligosynaptic pathway through which the $\mathrm{R} 1$ response is transmitted. Willer et $a l^{29}$ reported on the existence of a crossed trigeminofacial connection, and showed that a contralateral R1 response can easily be obtained in healthy subjects when the test stimulus was preceded
Test

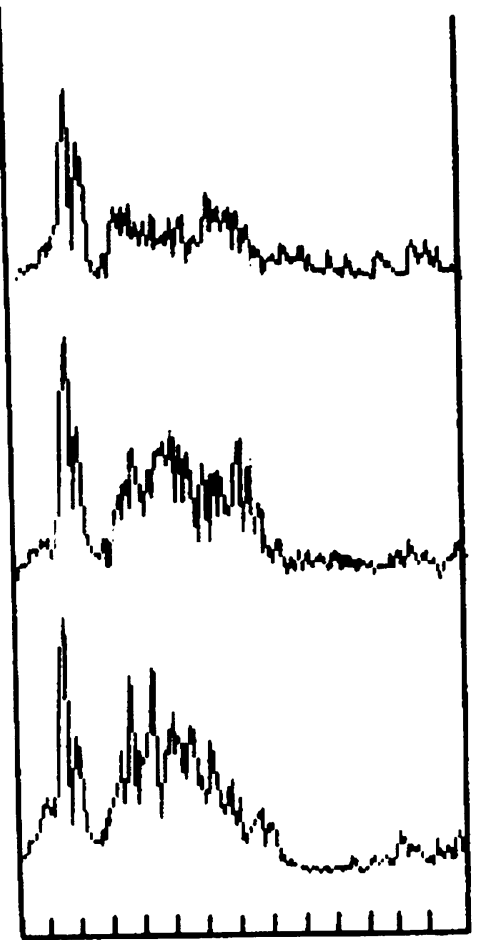

$10 \mathrm{~ms} / \mathrm{div}$

C

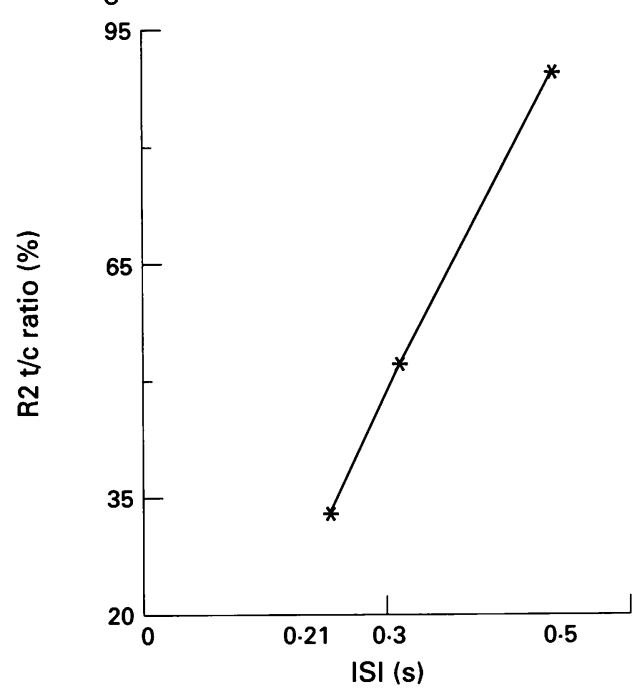

by an adequate conditioning stimulus. Yet after single stimulation of the supraorbital nerve, Berardelli et $a l^{16}$ recorded a contralateral R1 response in six of 16 patients with blepharospasm. Based on these data, it seems that at least the crossed oligosynaptic route mediating the contralateral $\mathrm{Rl}$ response is hyperactive in some patients with blepharospasm. Therefore, we agree with the conclusion of Tolosa et $a^{15}$ that the facial motoneurons themselves are not hyperactive in patients with blepharospasm. We presume instead that the interneurons involved in the generation of both the $R 1$ and $R 2$ responses may be hyperexcitable.

The pathways through which the basal ganglia can modulate the blink reflex are unknown. It seems, however, that the basal ganglia exert an inhibitory influence on the bulbar interneurons, even if it occurs 
Figure 2 (A) Rectified and averaged $(6 \times)$ EMG responses at intervals $0 \cdot 5,0 \cdot 3$, and $0 \cdot 21$ seconds between the conditioning and test stimuli, in a patient from $E M G$ subclass 2 . Recovery curve for $R 1$ (B) and $R 2$ (C) in the same patient. The recovery of $R 1$ and $R 2$ responses are normal at all three intervals. $I S I=$ interstimulus interval; $t / c$ ratio $=$ test response/conditioning response.
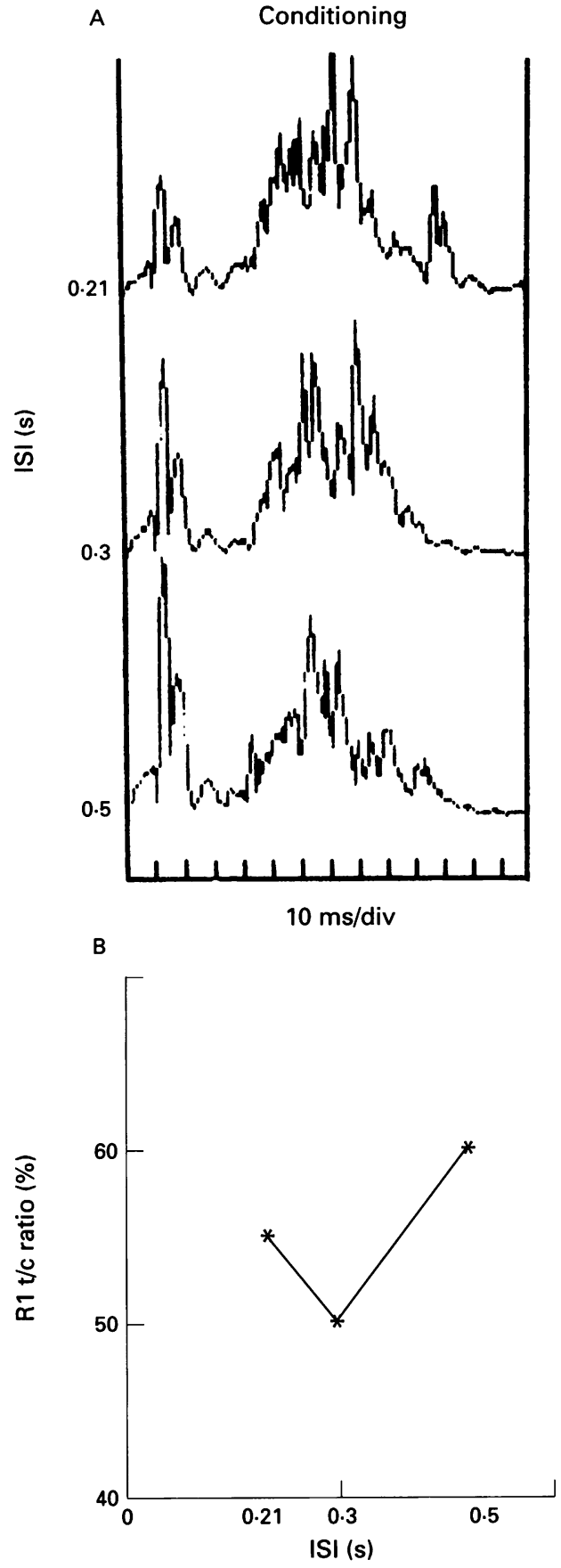

indirectly via cortical pathways because lesions of these pathways can suppress the blink reflex. ${ }^{11} 3031$ Evinger et al ${ }^{32}$ showed that apomorphine, a dopamine receptor agonist, and nicotine, which releases dopamine in the striatum, increase the latency of the $R 2$ response without altering the latency of the $\mathrm{R} 1$ response. In their recent paper, Basso et $a l^{26}$ showed that partial or even complete lesions of the substantia nigra and ventral tegmental area in rats do not modify the R1 recovery at all, whereas $R 2$ recovery shows pronounced excitability. Accordingly, in patients with Parkinson's disease R1 recovery is normal, ${ }^{1433} \mathrm{R} 2$ recovery is enhanced, ${ }^{14} 3334$ and R2 latency is shortened. ${ }^{14}$ Furthermore, patients with Huntington's disease exhibit a decrease in blink reflex excitability ${ }^{34}{ }^{35}$ and an increase in the latency of the $\mathrm{R} 2$ response, ${ }^{34-36}$
Test

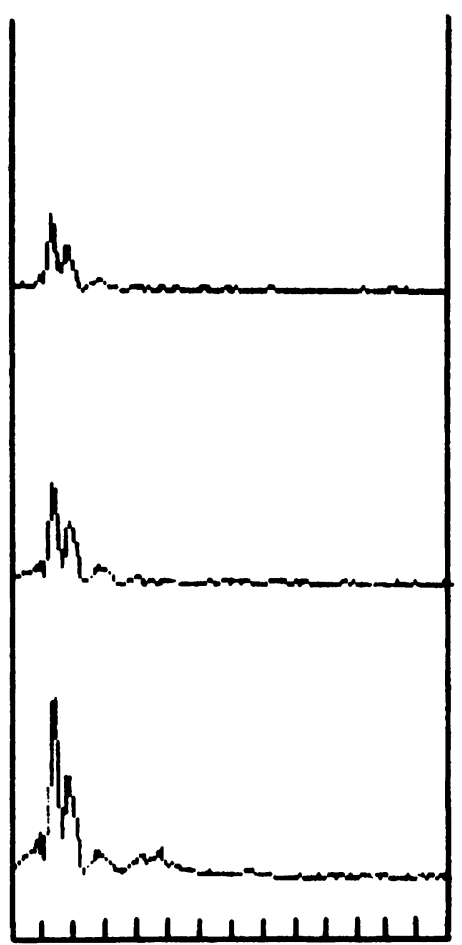

$10 \mathrm{~ms} / \mathrm{div}$

C

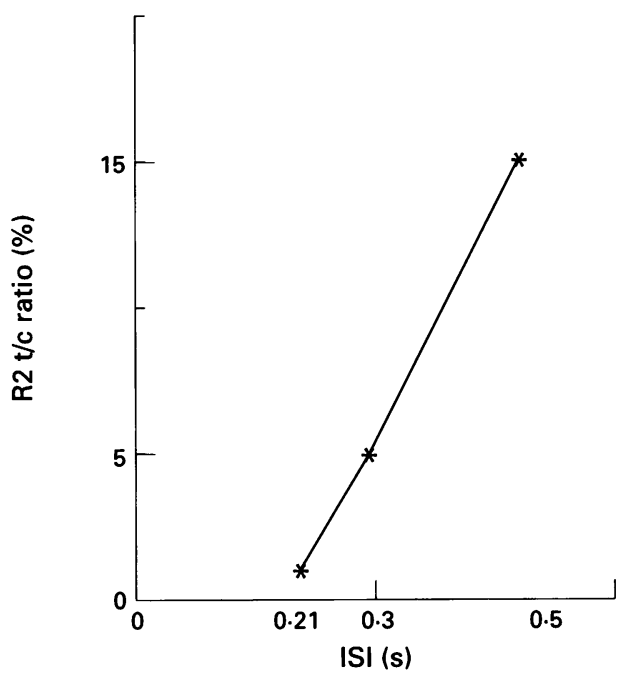

comparable with those findings in patients with hemispheric lesions. By contrast, R1 recovery was enhanced in our patients and the previous studies showed that the latency of R2 is normal in patients with blepharospasm. ${ }^{15-17}$ Based on these findings, two important conclusions can be drawn. Firstly, it is conceivable that dopaminergic activity of at least the substantia nigra may not control the state of activity of facial motoneurons directly or indirectly, through the oligosynaptic reflex pathway, and that the enhanced R1 recovery in our patients as a group should have some other origin. Secondly, it is possible that alterations in basal ganglia activity influence the bulbar interneurons somehow differently in patients with idiopathic blepharospasm from those patients with known diseases of the basal ganglia such as Parkinson's disease. 
A causal relation between hyperexcitability of interneurons and the occurrence of involuntary discharges in orbicularis oculi becomes less evident when we consider the data of R1 and $R 2$ recovery indices in individual patients or in patients from different EMG subclasses. Our results showed a normal R1 recovery index in $64 \%$ and a normal $\mathrm{R} 2$ recovery index in $54 \%$ of the total patient group, despite the fact that 30 out of 33 patients had involuntary discharges in orbicularis oculi, whether or not in combination with involuntary levator palpebrae inhibition (EMG subclasses 1 and 2). An abnormal $R 1$ recovery index occurred significantly more often in patients with an abnormal R2 recovery index. An interesting finding was that all patients with blepharospasm alone (EMG subclass 1), had an abnormal $\mathrm{R} 2$ recovery index and $50 \%$ also had an abnormal $R 1$ recovery index. On the other hand, those patients with involuntary discharges in orbicularis oculi with either involuntary levator palpebrae inhibition or a disturbed reciprocal innervation of orbicularis oculi and levator palpebrae (EMG subclass 2), often had normal $R 1$ and R2 recovery indices. At the time of this study, seven out of 20 patients from EMG subclass 2 were already under treatment with botulinum $\mathrm{A}$ toxin. It is unlikely that this influenced the recovery values in these patients, because previous studies ${ }^{1837}$ showed no difference in the blink reflex excitability in patients with blepharospasm before and after such treatment. Furthermore, it is also unlikely that patients with blepharospasm alone may have had a severe form of orbicularis oculi muscle dystonia, because as noted by Pauletti et al, ${ }^{17}$ there is no correlation between the severity of dystonia and the excitability of the blink reflex. The most probable explanation is a difference in underlying pathophysiological mechanisms. There may be a dissociation of the suprasegmental controls resulting in involuntary orbicularis oculi contraction, whether or not accompanied by disturbed levator palpebrae muscle activity, which cannot be examined by simply eliciting the blink reflex. Dissociation between innervation of emotional and voluntary movements of the facial musculature is well recognised in patients with central facial paresis, and with thalamic or pallidal lesions. ${ }^{38} 39$ Symptomatic blepharospasm may occur in disorders of the basal ganglia but never, to our knowledge, as an isolated abnormality. Conversely, no study has yet provided clear evidence for any pathology of the basal ganglia and their involvement in the generation of involuntary contractions of the eyelids in patients with idiopathic blepharospasm. On the other hand, Siegel et al ${ }^{40}$ reported on cells, located within a portion of the medial reticular formation, which showed discharges in relation to the closing movements of eyelids. The authors mentioned that some of these cells probably project directly to the facial cells and some may relay their outputs over multisynaptic pathways. In another report, Siegel et $a l^{41}$ also proposed that local interaction of these medial reticular formation cell populations may allow synthesis of the simple reflex movements generated in the brain stem. We suggest that besides the abnormal drives exerted by the basal ganglia, disorders of the segmental structures may also contribute to the enhanced excitability of the blink reflex responses and to the generation of blepharospasm. This assumption may explain why the recovery of $R 1$ and $R 2$ responses was often enhanced in patients with blepharospasm alone, who also often had dystonia of other cranial muscles without additional clinical features pointing to abnormal basal ganglia activity.

All three patients from EMG subclass 3, with involuntary levator palpebrae inhibition, had normal R1 and R2 recovery indices. These patients also had abnormalities of, among others, the basal ganglia. Therefore, certain disorders of the basal ganglia may influence the tonic activity of levator palpebrae muscle without altering the excitability of the blink reflex. We are unaware of any previous reports on this issue.

In conclusion, the results of the present paper are in agreement with our earlier findings, ${ }^{192042}$ and provide further evidence that, physiologically, blepharospasm is not a homogeneous disease entity. They indicate that various pathophysiological mechanisms at the suprasegmental, or segmental, level, or both, are involved.

We thank Drs L Volger and A Hilgevoord for their help in statistical analysis.

1 Marsden CD. Blepharospasm-oromandibular dystonia syndrome (Brueghel's syndrome): a variant of adultonset torsion dystonia? $₹$ Neurol Neurosurg Psychiatry 1976;39:1204-9.

2 Jankovic J, Ford J. Blepharospasm and orofacial-cervical dystonia: clinical and pharmacological findings in 100 dystonia: clinical and pharmacological

3 Fahn S, Marsden CD, Calne B. Classification and investigation of dystonia. In: Marsden CD, Fahn S, eds. Movement disorders 2. London: Butterworths, 1988 332-58.

4 Grandas F, Elston J, Quinn N, Marsden CD. Blepharospasm: a review of 264 patients. I Neurol Neurosurg Psychiatry 1988;51:767-2.

5 Jankovic J. Etiology and differential diagnosis of blepharospasm and oromandibular dystonia. Adv Neurol 1988 49:103-16.

6 Fahn S. Blepharospasm: A form of focal dystonia. $A d v$ Neurol 1988;49:125-35.

7 Jankovic J, Patel SC. Blepharospasm associated with brainstem lesions. Neurology 1983;33:1237-40.

8 Leenders KL, Frackowiak RSJ, Quinn N, Brooks D Sumner D, Marsden CD. Unilateral blepharospasm and contralateral hemidystonia and parkinsonism in a patient contralateral hemidystonia and parkinsonism in a patient with a unilateral rostral brainstem-thalamic lesion: structural and functional abnormalities studied with

9 Ongerboer de Visser BW, Kuypers HGJM. Late blink reflex changes in lateral medullary lesions. An electrophysiological and neuroanatomical study of Wallenberg's syndrome. Brain 1978;101:285-94.

10 Ongerboer de Visser BW, Cruccu G. Neurophysiologic examination of the trigeminal, facial, hypoglossal, and spinal accessory nerves in cranial neuropathies and brain stem disorders. In: Brown WF, Bolton CF, eds. Clinical electromyography. Pennsylvania: Butterworths, 1993: 61-92.

11 Ongerboer de Visser BW. Comparative study of corneal and blink reflex latencies in patients with segmental or with central lesions. In: Desmedt JE, ed. Motor control mechanisms in health and disease. New York: Raven Press, mechanisms in

12 Kimura J, Lyon LW. Orbicularis oculi reflex in Wallenberg syndrome: alteration of the late reflex by lesion of the spinal tract and nucleus of the trigeminal nerve. $\mathcal{F}$ Neurol Neurosurg Psychiatry 1972;35:228-33.

13 Kimura J. Alteration of the orbicularis oculi reflex by pontine lesions: study in multiple sclerosis. Arch Neurol 1970;22:156-61.

14 Kimura J. Disorders of interneurons in parkinsonism. The orbicularis oculi reflex to paired stimuli. Brain 1973; 96:87-96. 
15 Tolosa E, Montserrat L, Bayes A. Blink reflex studies in focal dystonias: enhanced excitability of brainstem interneurons in cranial dystonia and spasmodic torticollis. Mov Disord 1988;3:61-9.

16 Berardelli A, Rothwell JC, Day BL, Marsden CD. Pathophysiology of blepharospasm and oromandibular Pathophysiology of blepharospasm
dystonia. Brain 1985;108:593-608.

17 Pauletti G, Berardelli A, Cruccu G, Agostino R, Manfredi $M$. Blink reflex and the masseter inhibitory reflex in patients with dystonia. Mov Disord 1993;8:495-500.

18 Cohen LG, Hallett $M$, Warden $M$, Dambrosia J Excitability of blink reflexes in patients with blepharospasm after successful treatment with botulinum toxin. Ann Neurol 1987;22:172.

19 Aramideh M, Ongerboer de Visser BW, Devriese PP, Bour LJ, Speelman JD. Electromyographic features of levator palpebrae superioris and orbicularis oculi muscles in blepharospasm. Brain 1994;117:27-38.

20 Aramideh M, Ongerboer de Visser BW, Koelman JHTM Bour LJ, Devriese PP, Speelman JD. Clinical and electromyographic features of levator palpebrae superioris muscle dysfunction in involuntary eyelid closure. Mov Disord 1994;9:395-402.

21 Lepore FE, Duvoisin RC. Apraxia of eyelid opening: an involuntary levator inhibition. Neurology 1985;35:423-7.

22 Lepore FE. So-called apraxias of lid movement. $A d v$ Neurol 1988;49:85-90.

23 Goldstein JE, Cogan DG. Apraxia of lid opening. Arch Ophthalmol 1965;73:155-9.

24 Shahani B. Effects of sleep on human reflexes with a double component. I Neurol Neurosurg Psychiatry 1968;31: $574-9$.

25 Sunohara N, Tomi H, Satoyoshi E, Tachibana S. Glabella tap sign. Is it due to a lack of R2-habituation? $\mathcal{F}$ Neurol Sci 1985;70:257-67.

26 Basso MA, Strecker RE, Evinger C. Midbrain 6-hydroxydopamine lesions modulate blink reflex excitability. Exp Brain Res 1993;94:88-96.

27 Darian-Smith I. Presynaptic component in the afferent inhibition observed within trigeminal brain-stem nuclei inhibition observed within trigeminal brain

28 Stewart DH Jr, Scibetta CJ, King RB. Presynaptic inhibition in the trigeminal relay nuclei. $\mathcal{F}$ Neurophysiol 1967:30:135-53.

29 Willer JC, Boulu P, Bratzlavsky M. Electrophysiological evidence for crossed oligosynaptic trigemino-facial connections in normal man. $\mathcal{F}$ Neurol Neurosurg Psychiatry 1984;47:87-90.
30 Kimura J, Wilkinson JT, Damasio H, Adams HR, Shivapour E, Yamada T. Blink reflex in patients with hemispheric cerebrovascular accident (CVA). Blink reflex in CVA. I Neurol Sci 1985;67:15-28.

31 Berardelli A, Accornero N, Cruccu G, Fabiano F, Guerrisi V, Manfredi M. The orbicularis oculi response after hemispheral damage. $\mathcal{F}$ Neurol Neurosurg Psychiatry 1983;46:837-43.

32 Evinger C, Basso MA, Manning KA, Sibony PA, Pellegrini JJ, Horn AKE. A role for the basal ganglia in nicotinic modulation of the blink reflex. Exp Brain Res 1993;92:507-15.

33 Agostino R, Berardelli A, Cruccu G, Stocchi F, Manfredi $M$. The corneal and blink reflexes in Parkinson's disease with on-off fluctuations. Mov Disord 1987;4:227-35.

34 Esteban A, Gimenez-Roldan S. Blink reflex in Huntington's chorea and Parkinson's disease. Acto Neurol Scand 1975;52:145-57.

35 Agostino R, Berardelli A, Cruccu G, Pauletti G, Stocchi F, Manfredi $M$. Correlation between facial involuntary movements and abnormalities of blink and corneal reflexes in Huntington's chorea. Mov Disord 1988; 3:281-9.

36 Bollen E, Arts RJHM, Roos RAC, Van Der Velde EA Buruma OJS. Brainstem reflexes and brainstem auditory Buruma OJS. Brainstem reflexes and brainstem auditory Neved responses in Hychiatry 1986;49:313-5.

37 Valls-Sole J, Tolosa ES, Ribera G. Neurophysiological observations on the effect of botulinum toxin treatmen in patients with dystonic blepharospasm. $\mathcal{f}$ Neurol Neurosurg Psychiatry 1991;54:310-3.

38 Monrad-Krohn GH. On facial dissociation. Acto Psychiatrica et Neurologica 1939;14:557-66.

39 Monrad-Krohn GH. On the dissociation of voluntary and emotional innervation in facial paresis of central origin. Brain 1924;47:22-35.

40 Siegel JM, Tomaszewski KS, Wheeler RL. Behavioral organization of reticular formation: studies in the unrestrained cat. II. Cells related to facial movements. f Neurophysiol 1983;3:717-23.

41 Siegel JM, Nienhuis R, Wheeler RL, McGinty DJ, Harper RM. Discharge pattern of reticular formation unit pairs in walking and REM sleep. Exp Neurol 1981;74:875-91.

42 Aramideh M, Bour LJ, Koelman JHTM, Speelman JD, Ongerboer de Visser BW. Abnormal eye movements in blepharospasm and involuntary levator palpebrae inhibition: clinical and pathophysiological considerations. Brain 1994;177:1457-74.

\section{Cervicogenic headache: an early description}

Despite the controversies surrounding the clinical sources and pathological basis for cervicogenic headache, this term was used by, and often is attributed to Otto Sjaastad, ${ }^{12}$ although Barré and Riff had earlier described headache and vertigo, related to cervical arthritis, ascribed to stimulation of the vertebral nerve. ${ }^{3}$ However, an impressive, but little known description is found in the fourth of 18 lectures given between 1860 and 1862 on Rest and Pain, in John Hilton's classical text ${ }^{4}$ :

"Suppose a person to complain of pain upon the scalp, is it not very essential to know whether that pain is expressed by the fifth nerve or by the great or small occipital? Thus pain in the anterior and lateral part of the head, which are supplied by the fifth nerve, would suggest that the cause must be some- where in the area of distribution of the other portions of the fifth nerve. So if the pain be expressed, the cause must assuredly be connected with the great or small occipital nerve, and in all probability depends on disease of the spine between the first and second cervical vertebrae."

$$
\begin{array}{r}
\text { J M S PEARCE } \\
305 \text { Beverley Road, } \\
\text { Anlaby, Hull H1O } 7 B G, U K
\end{array}
$$

1 Sjaastad O. Headache and the influence of stress. A personal view. Ann Clin Res 1987;19:122-8.

2 Sjaastad O. Cervicogenic headache: the controversial headache. Clin Neurol Neurosurg 1992;94(suppl):S147-9. 3 Barré JA, Riff P. Le vertige qui fait entendre de Lermoyez étude des fonctions vestibulaires à propos d'un cas typique; rôle possible de l'irritation du nerf vertébra par arthrite cervicale, Revue Oto-neuro-ophthalmolog 1926 ; 4:498-501

4 Hilton J. Rest and pain. Walls EW, Phillips EE, eds. London: Bell, 1950:77. 
1 Wu RM, Chang YC, Chiu HC. Acute triphenyltin intoxication: a case report. $\mathrm{F}$ Neurol Neurosurg Psychiatry 1990;53:356-7.

2 Bock R. Triphenyltin compounds and their degradation products. Residue Reviews, 1981;79:31-270.

3 Stoner HB. Toxicity of triphenyltin. $\mathrm{Br} F$ Ind Med 1966;23:222-9.

4 Ascher KRS, Ishaaya I. Antifeeding and protease- and amylase-inhibiting activity of fentin acetate in Spodoptera littoralis larvae. Pesticide Biochemistry and Physiolog 1973;3:326-36.

5 Selwyn MJ. Triorganotin compounds as ionophores and inhibitors of iron translocating ATPase. In: Zuckerman JJ, ed. Advances in chemistry series. Vol 157. Washington DC: American Chemical Society 1976:204-26.

6 Manzo L, Richelmi P, Sabbioni E, et al. Poisoning by triphenyltin acetate: report of two cases and determination of tin in blood and urine by neutron activation Toxicol 1981;18:1343-53.

Cavanagh replies:

Having read Wu's reply to my earlier criticism I still think that this case should not be regarded as anything more than "suspected triphenyltin intoxication". There are too many uncertainties for the conclusions to be anything firmer. One important uncertainty is the remarkably slow though sustained evolution of the signs of change in the nervous system. While ataxia and blurred vision were early events, it was two weeks before he slipped into semicoma in November and he lay in coma virtually until the beginning of February. Signs of peripheral neuropathy developed two months after admission and persisted for several months more. The pattern of the neuropathy suggested an axonal mechanism whereas the electrophysiology gave evidence of myelin loss. Another uncertainty is the dose the subject absorbed, which is unknown, nor do we have any blood concentrations. Although it might seem from the reports that animal studies support the suggestion that triphenyltin can be neurotoxic, when such studies are unaccompanied by thorough morphological work interpretation is always very difficult and experience strongly suggests that these should be taken with the proverbial pinch of salt, especially when they have not been confirmed by others.

Triphenyltin compounds are widely used in the field and are generally considered to be free of serious neurological side effects, unlike trimethyl and triethyl compounds each of which produces its own pattern of affected cell types. On available evidence it is to be doubted whether there will be any future occasion when the claim of $\mathrm{Wu}$ and his colleagues will be supported, but should this happen I am content that this discussion and my initial reservations will be quoted. JP CAVANAGH

\section{NOTICES}

Stanley Foundation Research Awards Program

Announcement of available research funds for research on schizophrenia and bipolar disorder

The Theodore and Vada Stanley Foundation, in collaboration with the National Alliance for the Mentally Ill, wel- come applications for the 1996 Stanley Foundation Research Awards Program. The purpose of the awards is to support research directly related to the causes or treatment of schizophrenia and bipolar disorder.

The research awards are intended to attract established scientists from other areas of biology and medicine (for example, biochemistry, immunology, virology, and neurology) into research on schizophrenia and bipolar disorder as well as to provide support for innovative research by scientists already in the field whose funding sources are limited. Applicants are invited from all stages of career development.

Awards are for one or two years. They may be up to $\$ 75000$ per year for studies involving human subjects and up to $\$ 50000$ per year for other studies. Funds may be used for salaries, supplies, and equipment, but it is the policy of the Stanley Foundation not to pay indirect costs for administration of the award. In 1995, 49 applications were funded out of a total of 220 received.

Deadline for receipt of applications is 1 March 1996. The 4 page application consists of a brief outline of the proposed project, a budget, and a list of current and pending sources of funding. Notification of awards is made in June and funding to award recipients begins in August.

The research award applications are reviewed by a professional selection committee.

Requests for applications and questions should be directed to: Research Awards Coordinator, Stanley Foundation Research Awards Program, c/o NAMI, 200 North Glebe Road, Suite 1015, Arlington, VA 22203-3754, USA. Tel (703) 524-7600; fax (703) 524-9094

Sixth Meeting of the European Neurological Society June 8-12 1996 Netherlands Congress Centre, The Hague, The Netherlands.

Administrative Secretariat ENS 1996, c/o AKM Congress Service, PO Box, 4005 Basel, Switzerland, Tel ++416169151 11, Fax: ++416918189.

British Neurosurgery Research Group Meeting together with the North American Research Society of Neurological Surgeons Meeting, 1996.

This joint meeting will be held in Newcastle upon Tyne, 23-25 May 1996.

For further information contact: Professor A David Mendelow, Newcastle General Hospital, Westgate Road, Newcastle upon Tyne NE4 6BE, UK.

World Federation of Neurosurgical Societies

Awards to young neurosurgeons.

The World Federation of Neurosurgical Societies will give five awards to young neurosurgeons for the best papers submitted for presentation at the XI International Congress of Neurological Surgery to be held in Amsterdam, Netherlands 6-11 July 1997. This will be open to all neurosurgeons born after 31 December 1961. Each award will consist of an honorarium of US $\$ 1500$, a certificate for the Congress. The papers will be judged by a committee and must contain original, unpublished work on basic research or clinical studies related to neurosurgery.

Young neurosurgeons should submite eight copies of the manuscript (not more than 10 double spaced typewritten pages exclusive of figures and tables) to:

Albert L Rhoton, Jr, MD Chairman, WFNS Young Neurosurgeons' Committee, Department of Neurological Surgery, University of Florida Medical Center, PO Box 100265; 1600 SW Archer Road Gainesville, Florida 32610-0265, USA.

The submission should be accompanied by a supporting letter from the head of the candidate's neurosurgical department. The last date for submission is 1 October 1996.

Announcement from the British Neuropsychiatry Association: 1996 meetings

The 1996 Winter meeting-a joint meeting with The British Neuropsychological Society-will be held on Friday 19 January at the London Zoo. "Disorders of reasoning and perception" is the theme of the morning session and there will be presentation of short scientific papers and single case videos by members of both associations in the afternoon.

The 1996 Summer meeting will be held on 14-16 July at Robinson College, Cambridge. It will include topics on neurodevelopment, language, and the presentation of short scientific papers and single case videos by members. The Association's AGM will be held on 16 July.

For further details of these meetings please contact: Sue Garratt, Administrative Assistant, BNPA, 17 Clocktower Mews, London N1 7BB. Telephone/Fax: 0171226 5949.

For details of membership of the BNPA, which is open to medical practitioners in psychiatry, neurology, and related clinical neurosciences, please contact: Dr fonathan Bird, Secretary BNPA, Burden Neurological Hospital, Stoke Lane, Stapleton, Bristol, BS16 1OT. Telephone: 01179701212 ext 2925/2929 or Sue Garratt at the address given above.

CORRECTIONS

Catarci T, Lenzi GL, Cerbo R, Fieschi C. Sumatriptan and daily headache. $\mathcal{F}$ Neurol Neurosurg Psychiatry 1995;58:508.

The reference to Osborne et al should be $B M F$ 1994;308:113.

Aramideh M, Eekhof JLA, Bour LJ, Koelman JHTM, Speelman JD, Ongerboer de Visser BW. Electromyography and recovery of the blink reflex in involuntary eyelid closure: a comparative study. $f$ Neurol Neurosurg Psychiatry 1995;58:692-8.

In table 2 (bottom line) the mean $\mathrm{R} 2$ index (range) in the third EMG subclass should be $31(28-37)$ 